\title{
Images of the Future from the Past: The Metabolists and the Utopian Planning of the 1960s
}

\author{
Raffaele Pernice \\ Department of Urban Planning and Design, Xi'an Jiaotong-Liverpool University, Suzhou 215123, China
}

\begin{abstract}
During the 1960s, many changes reshaped the economy, the society and the arts. The Cold War, the Space Race, the construction of a new middle class in most western societies led by the postwar economic prosperity with unprecedented urban growth followed by severe environmental problems fostered the design of spectacular urban utopian cities and mega-architectures. In those years, Japan was the source of highly influential bold and visionary urban and architectural ideas which relied on advanced technology. These ideas were conceived on the thought that cities could be seen as gigantic but impermanent entities able to transform itself according to an organic process of adaptation of its elementary components. This paper briefly revisits and critically discusses the legacy of the iconic mega-structural projects of Japanese Metabolist Movement and other visionary architects and planners of the 1960s, such as Paolo Soleri, Buckminster Fuller, Archigram. It attempts to enlighten the continuity with contemporary innovative and experimental urban models and ideas for the society and the city of the future, such as the Smart Cities, Eco-Cities, Green Urbanism, whose design is led by concerns related to climate change, the necessity of energy efficiency, the improvement of urban landscape and the valorization of depleted natural resources.
\end{abstract}

Key words: Metabolist movement, urban utopias, marine city, megastructures, Japanese architecture, Modern Movement.

\section{Introduction}

The decade of the 1960s was a stage where many innovations and changes occurred: The Cold War and the Space Race, the seeds of the social revolt of the students and the postwar economic prosperity with unprecedented urban growth, the so-called Green Revolution, and the demographic explosion followed by a severe urban and environmental crisis. All these socio-cultural factors and the opportunities and threads related to the rapid change of the time promoted the design of spectacular new utopian cities and mega-architecture conceived as urban prototypes for a new era. The limits of design principles and urban methodologies developed by the Modern Movement since the 1920s and accepted all over the world after the end of WW II resulted in the epochal failures of urban renewal projects developed from the 1950s both in European and American cities, as stressed by many

Corresponding author: Raffaele Pernice, Ph.D., lecturer, research fields: architecture, urban design and city planning. E-mail: raffaeleitaly@yahoo.com. publications of the time and reported especially by 1961's Jane Jacobs' famous essay “The Death and Life of Great American Cities". The Modern Movement identified the ideal city with the functional city, and argued that good urban planning could have generated "good" architecture by means of the instrument of zoning, the crisis of this theoretical approach in the postwar years urged architects to withdraw from rationalist design methodology and to pursue the resolution of this impasse in search for formal invention, promoting, as pointed out by Italian critic Argan [1] "the technological boom of contemporary architecture". This condition worked as a catalyst for architectural proposals whose nature was in opposition to the rationalist program of scattered architectures in the city, and, in opposition to this approach, promoted the design of huge structures of super-human size and with a complex internal organization like that of a small city. One of the most radical and popular architectural and urban design trend during the early 1960s was therefore the development of the so-called 
"mega-structures" which originated a number of urban utopias and architectural prototypes based essentially on the blind trust in the power of modern technology. Such megastructures were considered as a key factor in the creation of an effective urban model which connected and integrated, in relation to the creative process for its design and development, both architectural and urban design considerations. Certainly, these technologically advanced mega-structures were regarded by designers as a kind of "panacea" to the evil of the chaotic city growth during the decade, and considered as the solution to the fundamental problem of the lack of legibility of the post-war industrial city and an effective instrument in designing an innovative urban landscape more responsive to the needs of a modern industrial, mass-oriented and consumerist society. The success of these urban prototypes was due to the importance of the social and technological revolution which occurred in those years and which promoted an extensive expansion of large urban infrastructures (motorways, factories, piers) and futuristic proposals in architecture. They also emphasized the role of mass transportation and the need for innovative urban and new engineered structures. These urban prototypes were presented as a solution suitable to overcome the limits in the conventional city planning approach due to the excessive fragmentation of urban land, giving the illusion of being able to control and plan the growth of the city and respond to its future needs thanks to the expansibility and changeability inherent their very nature of gigantic frames.

In Japan, the bold and visionary urban and architectural projects of the Metabolist Movement, a group of architects, designers and planners who were inspired by the advanced technology of the time and the idea of the city as an impermanent entity which transforms itself according to an organic process, mirrored the rapid economic growth and general transformation of postwar culture and society. Their manifesto titled "Metabolism 1960. Proposals for a
New Urbanism" was presented at the World Design Conference held in 1960 in Tokyo, a city that experienced for three times in few decades the total destruction caused by natural (Great Kanto Quake in 1923) and human actions (American bombing in 1944-1945 and then the spread of pollution in 1950s-1960s). From here sprang a new generation of poetic but pragmatic thinkers who wanted to reshape the urban environment of Japan and the cities of the world.

\section{The Metabolist Group and Kenzo Tange}

In their very essence, Metabolism's architectural and urban projects were sensitive to the changeability of space and functions of the Japanese context of the time, in opposition to the sense of immobility of fixed forms and functions of conventional modernist design. These projects were severely critical of the principles of the Athens Charter to control the design of the modern city, and they put a fundamental emphasis on the issues of the artificial land, the basic infrastructures (such as circulation and transport) and mass housing solutions. With few exceptions, the Metabolists (a group composed of architects Kiyonori Kikutake, Kisho Kurokawa, Masato Otaka, Fumihiko Maki, and critic and designers Noboru Kawazoe, Ekuan Kenji and Awazu Kyoshi) expanded the principles and the methodology of architectural design and composition into urban design. Their view of the city was a complex structure of interconnected systems of mass produced urban elements assembled in as organic shapes. Indeed the main feature of metabolist design approach to city places was the rejection of the traditional form of public urban spaces (squares, streets, neighborhoods) in favor of a totally artificial urban environment set into the natural landscape, as seen in Kurokawa's "Helix City" and Kikutake's several marine cities projects.

In their attempt to express the vitality, the optimism and the creative spirit of the modern Japanese postwar society driven by a rapid economic growth, the 
metabolists adopted the newest technological devices available, and conceived a city as being composed entirely of megastructures which denied any visual linkage with the preexisting urban environment and showed indifference to the physical context. Their urban schemes lacked of any recognizable clue of the formal order of the traditional city, either Japanese or Western. Expressing a strong opposition towards the memory of the recent history of Japan, as well as its urban environment, indeed promoted, with a touch of ingenuity and simplistic vision, an extreme and radical departure from city form towards a technological (better and optimistic) future shaped like in the pictures of the fiction science publications, so popular during the 1950s, which praised the achievements and the wonders of the contemporary (post-Hiroshima) atomic age. The futuristic and anti-traditional collection of ideas proposed by the main members of Metabolism were truly the mirror of a more general interest about the possibilities offered by the new technologies of building construction applicable in the creation of new artificial urban landscapes. The unprecedented extensive exploitation of the natural sites in Japan led to new opportunities of creativity for architects who could cause less damage to the natural sites by using new techniques developed in the field of oceanic engineering and port constructions.

The first proposal for a comprehensive urban reorganization of Tokyo based on key ideas of Metabolism was proposed by Kenzo Tange, a sort of mentor for the group, at the World Design Conference held in May 1960 under the title: "A Plan for Tokyo, 1960: Towards a Structural Reorganization” (Fig. 1). The theory of Structuralism, to which Tange referred, had its roots in the works about the science of Linguistics, and following that analogy to the written language, he tried to grasp the basic structure of the modern city, which he envisioned as the engine of economic growth and prosperity, as well as the fundamental environment for human life, in terms of mobility and conceived the communication channels as

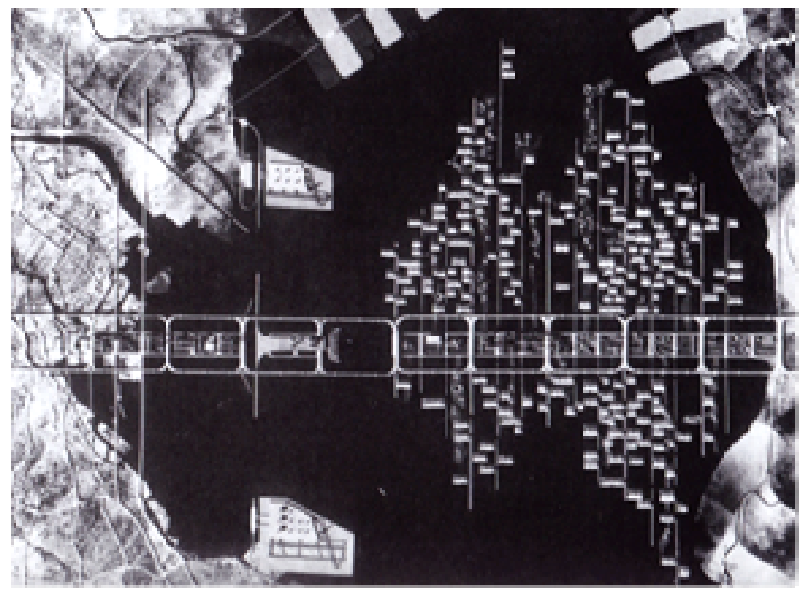

Fig. 1 Kenzo Tange, Tokyo Plan, 1961 [11].

the main urban structure which connects space units with shorter cycles of life [2]. The main feature of the project developed in 1960 was the rejection of the traditional radial pattern of urban growth, which dated since the foundation of Tokyo and that had been proposed for the post-war reconstruction plan of the city, and the substitution of this centripetal model of expansion with a linear model of development across the Tokyo Bay, inspired by the European tradition of linear city, proposing a scheme which aimed at transforming Tokyo following a kind of metabolic evolution from the form of an amoeba-shape to that of a vertebra or city axis [3], creating a new pattern for the contemporary city which could achieve a balanced relation between major urban infrastructures and minor architectural clusters.

The special linkage between Japan and the megastructures has been well put in evidence by Reyner Banham, who pointed out that the first official definition of this kind of architecture was suggested by Japanese architect Fumihiko Maki, at that time also member of the Metabolist Group, as well as the fact, as he noted, that the same World Design Conference held in Tokyo in 1960 was a deliberate attempt to present the megastructure as a specific Japanese contribution to the modern architecture theories thanks to the projects presented by Metabolists and Tange [4].

In this sense, the scholar Robin Boyd has stressed the particular predilection of Japanese architects for the 
megastructures as urban structures suitable for the needs of Japanese society of the time, an interest for a new kind of buildings conceived as a fusion of architecture and urban environment that the many architects in Japan, especially the members of Metabolism, shared with the British group Archigram [5]. It cannot be denied however that many social, economic and cultural factors promoted the spread of megastructural ideas all around Japan during the 1950s and the 1960s. The new political and cultural direction embraced by Japan after the war was fundamental for the Japanese architectural context. Bognar [6] noted that: "After an age of expressive and sculptural formalism, designers in general became increasingly preoccupied with the elaboration of systematic design methodology and often futuristic industrial construction. Large-scale, utopian urban schemes became models for an architecture that was regarded as a testing ground for the latest technologies. Megastructures, interchangeability, and capsule architectures went from mere catchwords, to build realities, proving again that in Japan, more than elsewhere, new ideas are experimented with and developed on the construction site rather than on the pages of magazines and books or in school of architecture". The processes of postwar reconstruction and economic growth gave a strong stimulus for the development of large construction companies, which found many occasions for their further expansion thanks to the phenomenon of urbanism which enlarged the suburbs of all the main Japanese metropolises and created extended and dense urban fabrics. The need for new urban facilities and services promoted public competitions sponsored by the government which gave several chances for the diffusion of design concepts developed both by the researches of construction companies and by private professionals, fostering the growth of a more competitive housing and construction industry.

The high land prices in the big Japanese metropolises and the diffuse housing shortage were effective factors that fostered architects and urban planners to embrace the megastructural principles because it allowed concentrating a high amount of people and functions into fairly small areas.

\section{The Crisis of Modernism and the Debate over the Megastructures in the 1960s}

By the late 1950s, the failure of the design methodology developed by the masters of Modern Movement during the 1930s led towards the experimentation with new architectural theories (such as the "Structuralism", "Regionalism" and "Theories of Systems") and prototypes, which rejected the rationalist approach and the main prescriptions of the International Style [7]. The reasons which prompted strong criticism of the theories promoted by the masters of the International Style before the Second World War was clearly summarized by the architectural historian Spiro Kostof: "The validity of those untested international (modernist) solutions for the basic issue of living in cities looked questionable, both to the profession and those outside. Fresh observation by social planners, especially in the realm of public housing, showed conclusively (...) that users were unhappy with what the architects had deemed exemplary and imposed from above. Internally, the younger followers of the modernist line pushed for reforms. They challenged the universalist posture of the masters, their pretense of omniscience. (...) Total design had proved unpalatable. The call now was for variety, flexibility, the semblance at least of spontaneity" [8].

Whereas the Modern Movement identified the ideal city with the model of city planned according to a rational and functional design process, driven by the fundamental instrument of the zoning, the crisis of this theoretical approach seen in the evident failure of several projects for urban renewal and slum clearance in the postwar years prompted the architects to search for alternative form of planning and design; the economic boom and the unprecedented development of 
technology in those years pushed architects and planners to conceive proposals whose nature was in opposition to the typical Rationalist program of creating simple geometries and dissolving the architecture into a larger urban matrix, and instead fostered the design of huge structures and spaces with an urban-like complex internal organization.

As consequence among the most radical and popular architectural trend during the early 1960s was the development of the so-called "mega-structures", a kind of gigantic architectural prototypes built thanks to modern technology from different fields and seen as innovative urban modes which combined and integrated together architecture and city planning, creating a new urban landscape which heralded a potential and effective solution to the problem of exploding metropolis of the time.

In his "Urban Structures for the Future", a book published in 1970 as anthology aimed to collect many examples and models of the megastructural projects developed in the previous decade, Dahinden [9] described the "urban crisis" of the 1960s as the consequence of many factors basically related to the lack of flexibility of urban schemes of the contemporary cities which failed to cope with the dynamic society of the period composed by a population of "urban nomads". He pointed out that the problem caused by the concentration of population into the big metropolitan cities was the consequence of the urban sprawl promoted by the dynamics of change in the modern society and economy, and he suggested that it could have been possible to control this tendency by means of the use of "megastructures" and creating a compact, "dense" city which could gather into an organic frame the different social groups and activities, integrating together the urban structure and public and private activities of society; and also as noted by other scholars, distressed the importance of the social and technological revolution of the period which promoted futuristic proposals in architecture emphasizing the role of the mass transportation and innovative urban structures such as the megastructures, which were represented as solution suitable to overcome the limits in the city planning due to the excessive fragmentation of urban land, and capable of controlling the growth of the city and respond to its future needs thanks to their expansibility and changeability.

Although the projects spread all over the world showed a somewhat evident utopian character in the exasperation of the futuristic forms, indeed they were sensitive to the nature of the deep changes occurred into the realms of society, economy and cultural values of the time, as well in the diffusion of new theories and researches into new scientific disciplines. From early 20th century especially town planning reached a further level of complexity as new disciplines such as sociology, geography, economics influenced directly or indirectly its methodology of research requiring new competences and survey instruments.

Describing the development of town planning theories in Europe between the 18th and 20th centuries, the architectural historian Benedetto Gravagnuolo noted as after the first blow of urban reform promoted by "Utopians" such as Etienne Louis Boulle, Claude Nicolas Ledoux and others British social reformers, there were three main tendencies which influenced the urban schemes of European cities at the beginning of the last century: the "Garden City Movement", influenced by Ebenezer Howard's theories of urban decentralization of the existing cities and referred to the Picturesque aesthetics; the tendency which proposed the continuity with the traditional way of (European) urban growth without denying the value of the urban preexistence (such as in the projects of Hendrik Petrus Berlage in Amsterdam and Otto Wagner in Vienna); and at last the theories of the Modern Movement during the 1920s-1930s, which proposed the urban reformation of the cities by means of the policy of "tabula rasa" by rejecting completely their historical tradition and exalting the aesthetics of machine's world and the technological revolution, as stated in the early theories of Eugene Henard, Tony 
Garnier, the Italian Futurists and carried out by Le Corbusier, Walter Gropius and other modernists [10].

In spite of the inevitable differences due to the different cultural and contextual background, the deep connection that tied the theories of the masters of Modern Movement, the radical spirit of reform behind their ideas and the strong impact of their revolutionary projects on the solution to the problems of the traditional city and her relation with the modern age of "machine and technology", to the fundamental goals of the megastructural movement and its vision of a new form of urbanism proposed from the early years of 1950s until the end of the following decade. Indeed, many aspects behind the logic which supported the megastructures as dominant architectural trend and design during the 1960s in pursuing a real solution to the problem of modern city, as well as a way for the architects to overcome the "impasse" of the Rationalist ideology in the 1950s, are directly related to the cultural matrix of that modern design tendency starting with the origin of late 1920s CIAM (International Congress of Modern Architecture) theories and debates over the "minimum living", the "rational urban block" and the "functional city", whose revolutionary ideas revolved mainly around the key figure of Le Corbusier.

In his seminal work, "Megastructures: Urban Future of the Recent Past", Banham [11] indicated indeed Le Corbusier as the initiator of the megastructure trend in architecture. The project which set up this new tendency was the famous "Plan Obus for Algeri", which Le Corbusier designed in 1931, and it was the source from which sprung many other designs for complex urban projects in the following years, reaching the acme during the 1960s. In the project for Algeri, Banham [11] introduced as early general definition of the megastructure that of being a big structure composed by a huge primary frame containing many secondary interchangeable elements.

The interesting point was that the drawing for the Plan Obus denoted a total indifference for the architectural style of the objects inserted inside the frame of the primary structure (the dwellings), so that this project described clearly the essence of the megastructure as a dimensionally relevant "bookcase" containing an infinite quantity of secondary elements whose importance and relevance was insignificant compared to the main frame. The "macroform" of the main frame grew to spread over the territory of the city as far as the limit of her urban area and further, covering entire regions. Although Le Corbusier was among the first who influenced the development of the megastructures, the Japanese architect Maki [12], at that time member of the Japanese architectural movement "Metabolism", had the merit to formulate the first official definition for the word "megastructure". In his essay "Notes on Collective Forms" written in 1964, Maki [12] alleged that: "The megastructure is a large frame in which all the function of a city or a part of the city are housed. It has been made possible by present-day technology. In a sense, it is a human-made feature of the landscape. It is like the great hill on which Italian towns were built. Inherent in the megastructure concept, along with a certain static nature, is the suggestion that many and diverse function may be beneficially concentrated in one place. A large frame implies some utility in combination and concentration of functions".

Other scholars and architects tried to detect the characteristics of the megastructures, such as Ralph Wilcoxon, who specified in 1968 that this typology was dimensionally a big and large building, built by assembling modular units, had infinitive possibilities of growth, and was a long-lasting structural frame which could allocate minor elements (such as houses, small buildings and so on) which lasted less than the main frame and could be plugged in after being prefabricated elsewhere. Apart from the images of utopian schemes that proliferated in many projects, filled with imagines and forms often taken from the world of the fiction, it is possible to detect three simple solutions which became the main typological references for the designers and planners: the 
"tower-building", which can reach an unlimited height, the scheme of "artificial land" with a frame arisen from the ground by means of huge pillars which often contains the services, and the model of "linear city" as promoted by Le Corbusier for Algeri Plan and the "Unite", both capable of infinitive extension along their centre of gravity axis. Among those solutions, the former had a long tradition linked to the suggestions of American skyscrapers (which had as forerunners Luis Sullivan and the Chicago School in US, and Mies in Europe) and influenced many contemporary works such as those of Archigram and Metabolists groups; the second solution was presented in some proposals of Jona Friedman and the Japanese architect Arata Isozaki, both creating blocks of urban fabrics literally floating on the natural ground occupied by the preexistent city; the latter was the one which presented more similarity to the prototype developed by Le Corbusier (and may be more chances to be put into reality) and had to exert a profound influence on other architects, as showed in the case of the projects of the Paul Rudolph for the Lower Manhattan's Highway (1970). In this project, Rudolph drew a structure with a section shaped like an "A", dilating the space of the "street-corridors" of the Le original Le Corbusier project and transforming the inner corridors into a large communal central area, which was also reminiscent of previous famous projects such as Gropius's “Terrassenhauser-Project Wonhberg" (1928) and Tange's project for a residence settlement in the Boston Bay (1959).

\section{Main Typologies of Megastructures and Their Failure as Urban Prototypes}

By the early 1970s, it was the Swiss architect Dahinden [13] who attempted a more detailed classification of the various architectonic features and concepts used for the development of the megastructures. In his research on new models for the city of the future, he detected seven types of urban structures which followed different design and spatial principle. The classification of his "urban structures for the future" is listed the: Cellular Agglomerates, Clip-on/Plug-in structures, Bridge Structures, Containers, Marine Structures, Diagonal in the Space Structures and Biostructures.

The "Cellular Agglomerates" were composite structures consisting of integrated modular units which accepted additional units creating a macro-structures or spatial structure, whose final form depended on the position of the cells added. An example of this kind of megastructures was Safdie's "Habitat" [14], a project for residential units built in occasion of Expo 1967 in Montreal, and Alfred Neumann and Zvi Hecker Apartments block in Ramat Gad, Israel (1960). "Plug-in Structures" was by far the most popular typology of megastructures during the 1960s, which divided the structure of the building in a primary system and a secondary system, allowing easily changes and regeneration of the structural elements, and was promoted the "philosophy" of capsules which, according to general opinion of designers, were the ideal device to allow the maximum of individuality and privacy in a alienating society based on mass consumption. Typical examples of those structures were Archigram's "Plug-in City" (1964) (Fig. 2), Isozaki's Clusters in the Air (1961), Wolfgang Doring's "Stapelhaus" (1964), and the famous "Nagakin Tower" designed by Kisho Kurokawa (1972). The "Bridge Structures", built on vertical shafts which supported the entire spatial frame, derived from some modernist prototypes such as the Le Corbusier's "Unite' d'Habitation" and El Lissitzky's "Wolkenbugel". The modern versions of these early models were for example Isozaki's "City in the Air" (1960) and Jona Friedman's "Spatial City" (1960), who based his research on his "General Theory of Mobility". In the last one the main frame of the building presented a structural spatial grid suspended on huge pillars above the preexisting city. Inside this spatial grid, the secondary elements were easily in filled and moved like boxes. As examples of the 
typology of "Containers", which were an architectural structures capable of expand and contract, and create and control an internal microclimate, were Archigram's "Walking City" (1964) and Buckminster Fuller's geodesic domes, such as that for the American Pavilion at Montreal's Expo in 1967, and Frei Otto's light weight structures. "Marine Structures" were seen as an efficient and interesting solution to overcome the problems of soaring land prices and embodied the aspiration for a free and dynamic environment created on floating cities. Most of the projects of the time were conceived as prefabricated neighborhood modules made of steel and concrete (constructed in shipyards and towed to their destinations), which combined together created a growing system of interlocked structures which became eventually a larger city. Among the projects which shared this principle were the series of "Marine Cities" developed by Kiyonori Kikutake (1958-1962) (Fig. 3); the "Plan for Tokyo" proposed by Tange Kenzo (1960); the system of "Earthquakes Resistant Floating Towns" planned for Tokyo Bay, composed by hanging structures suspended on tall bridges, designed by French architect Paul Maymont (1960); Shoji Sadao and Buckminster Fuller's "Triton City" (Fig. 4), originally developed as a model of floating city for Tokyo Bay in the years 1963-1966; and Hal Moggridge, John Martin and Ken Anthony's "Sea City" (1968), well representative of the bold possibilities of this kind of urban structure designed to face and resist natural forces such as possible sea-level rise, earthquakes, strong tidal waves and typhoons.

The concept of "Diagonal in the Space" consisted in an urban schemes based on diagonal structural frames which supported terraced houses, which basically formed residential hills, such as in the project design by Cesare Pelli and A. Lumsden for the "High Density Terraced Town" in Sunset Mountain Park (1965), Walter Jonas's “Intrapolis" (1960), or Y. Akui, T. Nozawa and T. Akaiwa's "Neo-Mastaba", a project for renewal of Tokyo developed in 1961.
The last urban structure which Dahinden detected as a basic reference in the typology of megastructures was the "Biostructures", which, by combining the science of living matter (biology) with the science of architectonics (structures), referred to an ideal organic architecture directed "...towards a deeper appreciation

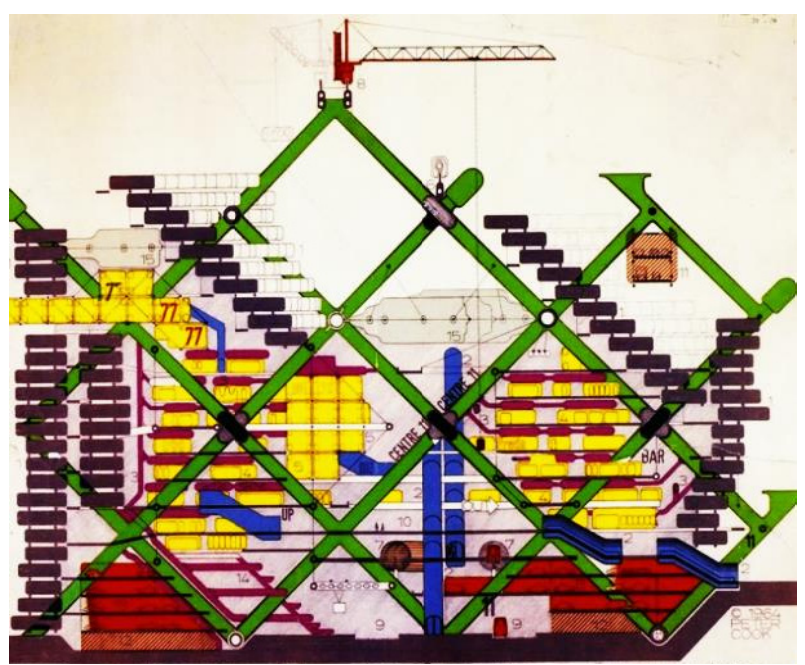

Fig. 2 Archigram, Plug-in City, 1964 [11].

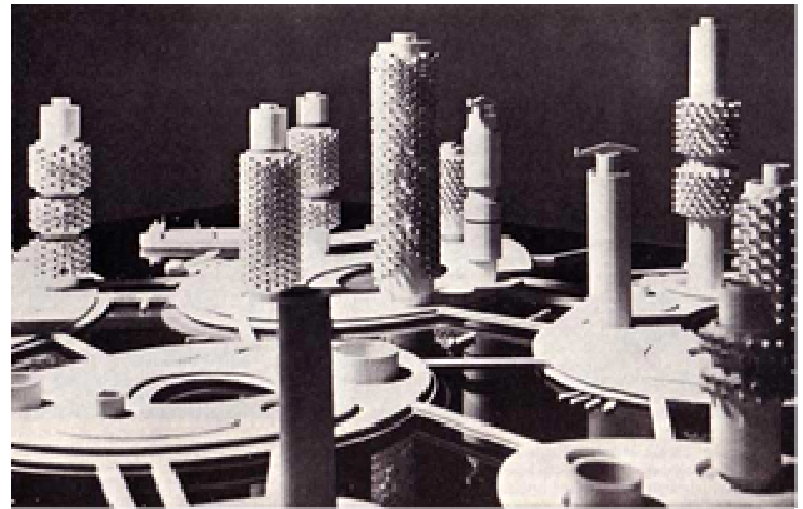

Fig. 3 Kiyonori Kikutake, Ocean City, 1962 [11].

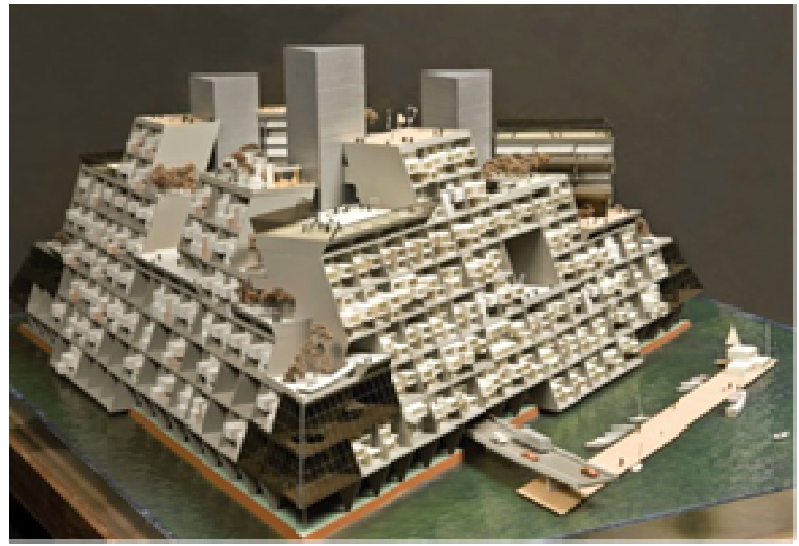

Fig. 4 Buckminster Fuller, Triton City, 1967 [11]. 
of the structural and functional correlation between nature and architecture" while "...(trying) to use our knowledge of the biological processes of origination, growth, cyclical change, decline and death in order to free architecture from its static role" [13]. This model of megastructure combined nature and human habitat, and had as its best representative the Italian architect Paolo Soleri, who developed his design theory based on the philosophical concept of "Arcology", a neologism which blended together the words "architecture" and "ecology", and intended to develop a kind of architecture which aimed to save the natural resources and start a new stage in the evolution of human society, creating a different kind of urban environment by means of a process of miniaturization and compactness of the modern cities as showed in his project of "Babelnoah" (1964).

The megastructures were indeed architectures too huge, complex to use, and caused great difficulty in the phase of management due to the high costs of maintenance. As noted by Kostof [8]: "Not only they were such project beyond the means of the world economy, they were also in the end, for all their pictures queness and seeming a formality, as oppressively programmed, as coercive, as the functionalist city they were determined to improve". In particular, a big failure was the idea to substitute the traditional structure of the neighborhood, typical of the old city, by means of the concentration of large amount of people and integrated services in big complexes of tall and compact buildings connected with each other and with the working places by means of motorways, which promoted the separation of the various functions of the city into specific areas, creating a big problem for the general mobility of the city, with crowded places and traffic congestion in some part of the city during the rush hours and total desert in residential areas during working hours. This urban approach sprang directly from the rigid vision of the Functionalistic City, which by many was simply conceived as an inhuman container of separated functions which gathered the similar activities in the same place and connected each area with mass and high-speed transportation networks. This questionable approach became more and more evident during the 1960 s, and a growing interest in the preservation of the old historical city and the need for a greater integration of urban functions and more efficient organization of the different social activities caught the attention of the more sensitive architects. The process of reform and rejection of the Rationalist approach as well as the Megastructural trend was reflected in the success and the influence of three important writings, an essay presented in 1965 and two books published in 1966: Alexander Christopher's "A City is not a Tree" (1965), Robert Venturi's "Complexity and Contradiction in Architecture", and Aldo Rossi's "L'architettura della citta" (The Architecture of the City). In his influential work, Christopher Alexander argued that the main urban pattern distinctive of the modernist urban plans was a "Tree", a structure which had a trunk, branches and leaves, capable of linear development and completely planned in its entirety by a single designer (such in the case of the plans by Le Corbusier and Tange). Such a structure lacks of flexibility, complexity and composite structure which can only be accomplished by a design process which involves other and diverse elements of design, which can generate a "semi-lattice" structure. Alexander defines the historical cities as "natural" cities, and he compares their structure to the "semi-lattice", which had been developed in time through multiple social, economic and historical factors, giving them their complexity and identity as urban settlements.

On the other hand, in his essay Rossi [15] praised the importance of the historical urban settlements and monuments as fundamental elements of the collective memories of the people, and led a further attack against the simplistic urban and architectural theories of International Style, as intended by the new generation of architects and witnessed by the mediocre realizations during the postwar reconstruction. He suggested that the 
form of the city was not a direct consequence of the urban functions of its urban elements, but on the contrary its form was strongly connected with the shape of the urban elements present inside its territory; the form of some urban elements was more important of functions which took place inside those forms, and among the urban elements which survived throughout the history of the city, the most important of all, those which are able to shape the city and its further development, were indeed the monuments.

The failure of the "dinosaurs of the Modern Movement", as Banham labeled the megastructures, apart any consideration on the reevaluation of the heritage of the historical city, indeed was linked to several other critical factors which were not taken, at least at the beginning, in serious consideration. In particular, it was the evident inhuman scale of their buildings and structures; the poor, superficial, and often unrealistic design theories based on a simplistic analysis of the contemporary mass-consumption society; the unacceptable condition of mono-cultural environment created by the megastructure as a city or a part of city designed by a single architect, and also the excessive confidence in the technological devises as infallible "deus ex machina" for effective solutions to the chaos of the modern city and its visual disorder. In this sense, it was perfectly understandable the comment given by Quaroni [16] about the general meaning of the whole movement and its failure, when he alleged that: "The need for new criteria for formal organization, new (architectural) languages, new possibilities for using the city has pushed many designers to overcome the limits of a false "continuity". From here (began) a production without precedent of adventurous projects, all of them full of indications, but in which it is difficult to distinguish what is acceptable from what is not, the true conceptual and intellectual breakthrough from the superficiality of a nonsense without value. In opposition to the superficiality of Maymont, Friedman, Jonas, Jellicoe there is the intent of criticism declared in the works of
Archigram and other similar groups, which however must be understood for its true meaning, within its limits of valuable "divertissement", as indication of a "compositional method" which is valid and possible beyond the static reduction to the elementary forms presents in the design approach of the last fifty years".

\section{Conclusions}

Reyner Banham assumed that the megastructural trend reached its peak in 1964 and had a further exploit at the Montreal Expo in 1967. Afterwards it began a period of progressive crisis for the whole ideology of this architectural trend, especially for its blind faith in the power of technology and supremacy of industry, and a general shift from a planning approach based on a comprehensive scientific view of the urban problems towards a prominent emphasis on the socio-economic development and the specialist and sectorial planning of the city. The progressive decadence of the idea of the megastructures was due to several external factors which prompted the economic crisis at the beginning of the 1970s (heralded by the 1973 Oil Shock and the consequent slowdown of the world economy), the growing spread of mortal diseases caused by industrial pollution, the uncontrolled exploitation of the natural environment, which attacked the myth of the "fair" and "clean" technology and industry, and to their "unsustainability", to use a word what stresses the present cultural and economic trend, inherent in most of those proposals; but ultimately it was also the failure of the simplistic urban, technological, economic and social vision behind the design approach on which the megastructures and its urban utopias relied and was typical of the historical period which saw the origin of this urban model.

The general criticism for the lack of human scale and the simultaneous revival of the importance of the history and the urban and social traditions of the people, which characterized the late 1960s, boasted a re-evaluation of the urban heritage and the preservation of the tradition (both as culture and space) and 
collective memory of the city and its society, and prompted a more cautious approach to the planning and design of the cities, causing a rethinking of the necessity and opportunity of the radical transformation of the urban environment pursued at all costs, together with the radical re-planning of space, economy and society, which the megastructural dream proposed. The end of economic expansion of the 1960s shifted the perceptions of the problems. New research reports and books like Rachel Carlson's "The Silent Spring" (1962) and The Club of Rome's "Limits to Growth" (1972), which condemned the effects of the extensive use of industrial pesticide in the natural environment and the unsustainable exploitation of the natural resources, and E.F. Shumacher's "Small is Beautiful" (1973), which championed a more "human" economic system alternative to the industrialist-capitalist model, outlined directly or indirectly the mistakes and ingenuity behind most of this sort of techno-social urban planning. Eventually these and other works stressed the growing gap between the aspiration towards a continuous urban and economic growth, on which the megastructures were based, and what was to become known as necessary sustainable growth at the end of 20th century.

\section{Acknowledgments}

Special thanks go to David Munn and Austin Williams for their comments in the preparation of the essay; this is a revised and extended version of the paper presented at 11th International Symposium on Advanced Technologies (ISAT-Special), Kogakuin University, Tokyo, in October 2012.

\section{References}

[1] G.C. Argan, L'Arte Moderna 1770-1970 (Modern Art
1770-1970), 1st ed., Sansoni Editore, Milano, 1981, pp. 609-612.

[2] K. Tange, A plan for Tokyo, 1960: Toward a structural reorganization, Shinkenchiku 36 (3) (1961) 99-101.

[3] R. Pernice, The issue of Tokyo Bay's reclaimed lands as the origin of urban utopias in modern Japanese architecture, Journal of Architecture and Planning (Transactions of AIJ-Tokyo) 613 (2007) 259-266.

[4] C. Wendelken, Putting the metabolism back in place, in: S.W. Goldhagen, R. Legault (Eds.), Anxious Modernist: Experimentation in Postwar Architectural Culture, Canadian Centre for Architecture, Montreal, The MIT Press, Cambridge, Massachusetts, 2000, p. 281.

[5] R. Boyd, New Direction in Japanese Architecture, G. Braziller, New York, 1968, pp. 14-15.

[6] B. Bognar, Nikken Sekkei: Building Future Japan, 1900-1990, Rizzoli International, New York, 2000, p. 50.

[7] J. Ockman, Architectural Culture: 1943-1968, Columbia Books of Architecture/Rizzoli, New York, 1993, p. 8.

[8] S. Kostof, A History of Architecture: Settings and Rituals, Oxford University Press, Oxford, 1985, pp. 743-745, 746-747.

[9] J. Dahinden, Urban Structures for the Future, Praeger Publisher, London, 1970, pp. 8, 11, 16.

[10] B. Gravagnuolo, La progettazione urbana in Europa 1750-1960 (Town Planning in Europe 1750-1960), Laterza, Bari, 1991, p. 13.

[11] R. Banham, Le Tentazioni dell'architettura. Megastrutture, Edizioni Laterza, Bari (Italian Edition of: Megastructure, Urban Future of the Recent Past, Thames and Hudson), London and New York, 1976, pp. 3-5, 44, 49, 118, 239-240.

[12] F. Maki, Investigation in collective forms, in: F. Maki (Ed.), Buildings and Projects, Princeton Architectural Press, St Louis, 1997, p. 210.

[13] J. Dahinden, Urban Structures for the Future, Praeger Publisher, London, 1970, pp. 19-40, 120.

[14] M. Safdie, W. Kohn, The City after the Automobile, Stoddart Publishing, Toronto, 1997, pp. 80-82.

[15] A. Rossi, L'Architettura della Citta' (The Architecture of the City), 1st ed. 1966, Citta' Studi Edizioni, Torino, 2004.

[16] L. Quaroni, La torre di Babele (Babel Tower), Marsilio Editore, Padova, 1982, p. 236. 